\title{
Conclusion and Afterword
}

\section{Introduction}

The book that you have just read contains a great deal of medical, socioeconomic, demographic, epidemiologic, racial, ethnic, educational, and cultural information pertaining particularly to the black population of the United States, but it is admittedly somewhat incomplete. There is so much more that might have been included, but space and time limitations preclude a more comprehensive coverage of everything that touches upon the healthcare scene involving black Americans. In this brief postscript, I would like to suggest to the reader to consider a few more important issues affecting black health.

\section{Additional Healthcare Issues Affecting the Black Community}

\section{Low Recruitment of Black Students into Medical Careers}

The problem of insufficient recruitment of African American students into careers in medicine is often referred to as the medical school "pipeline" problem, which has been highlighted by several incisive publications such as An American Crisis: The Growing Absence of Black Men in Medicine and Science, a book whose lead author was Cato T. Laurencin, MD, PhD, Rapporteur for the National Academies of Sciences, Engineering, and Medicine [1]. In the Proceedings of a Joint Workshop in which several prominent luminaries participated, it was pointed out that blacks, and black men in particular, are underrepresented among medical school applicants (Fig. 10.1) [2]. As Louis Sullivan, MD, Chairman and CEO of the Sullivan Alliance to Transform the Health Professions, noted in his keynote speech, although African Americans constitute $13 \%$ of the US population, they constitute only $7 \%$ of medical students and less than $3 \%$ of practicing doctors. In addition, we seem to be reversing course regarding the admission of black men to medical school; in 1978, 542 black males matriculated in medical schools compared to 515 blacks in 2014 


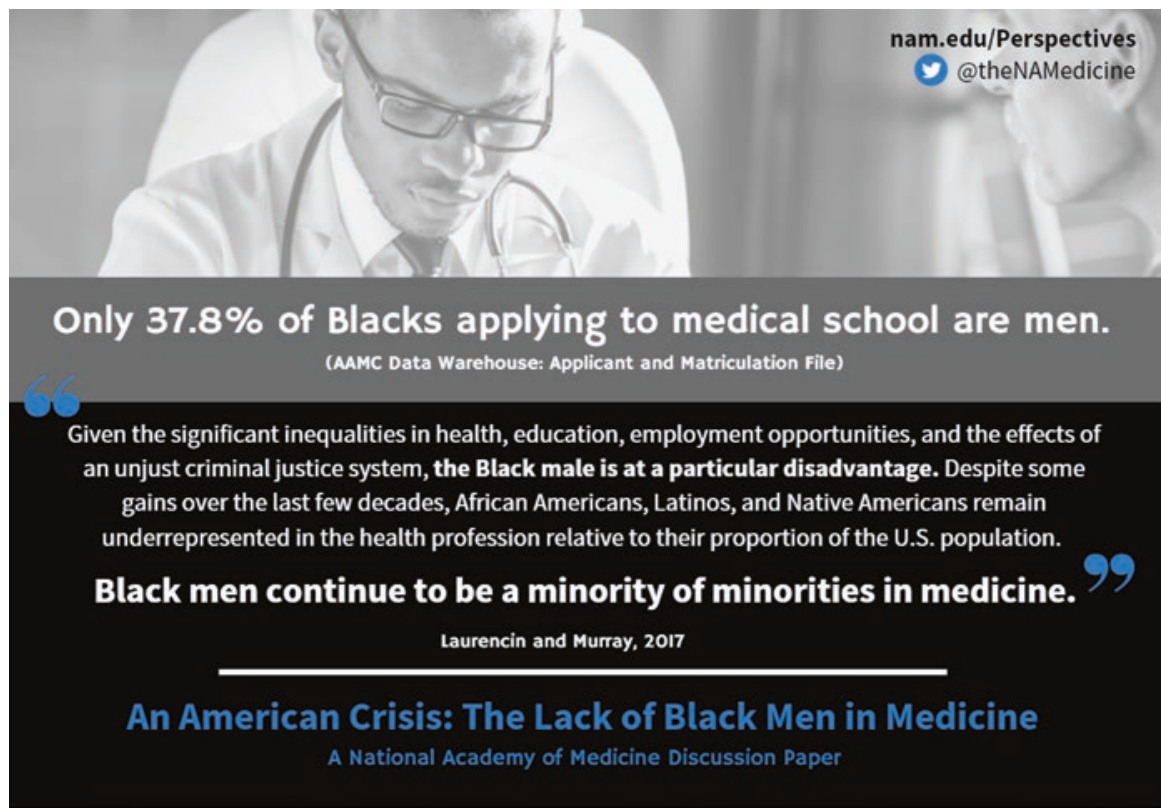

Fig. 10.1 Black males are not applying to medical schools in sufficient numbers. (Data from Laurencin and Murray [2]; graphic courtesy of the National Academy of Medicine https://nam. edu/an-american-crisis-the-lack-of-black-men-in-medicine/)

(Fig. 10.2) [2]. Thus, the pipeline has grown narrower, with insufficient numbers of black doctors eventually being produced. This has ramifications for the black community, since it has been shown that black patients elect to receive more preventive care when the providers are black as compared to when they are not [3]. In addition, physicians who are members of underrepresented groups are more likely than whites to serve poor, minority, and Medicaid populations [4]. There is also a need for more diversity in leadership positions in academic medicine. As stated by Cantor et al., "diversity improves patient care....promoting women and underrepresented minorities to leadership positions may well enable academic medicine to better serve our diverse population" [5]. Only $2 \%$ of full-time medical school faculty consists of black men, according to the Association of American Medical Colleges (AAMC).

\section{Violence in the Black Community}

Violence in the black community is a problem that has flown under the radar until recently, when the National Medical Association (NMA) created a task force to address it. The NMA's Working Group on Gun Violence and Police Use of Force, of which I was a member, was led by national co-chairs Roger A. Mitchell, Jr., MD, Chief Medical Examiner for the District of Columbia, and 


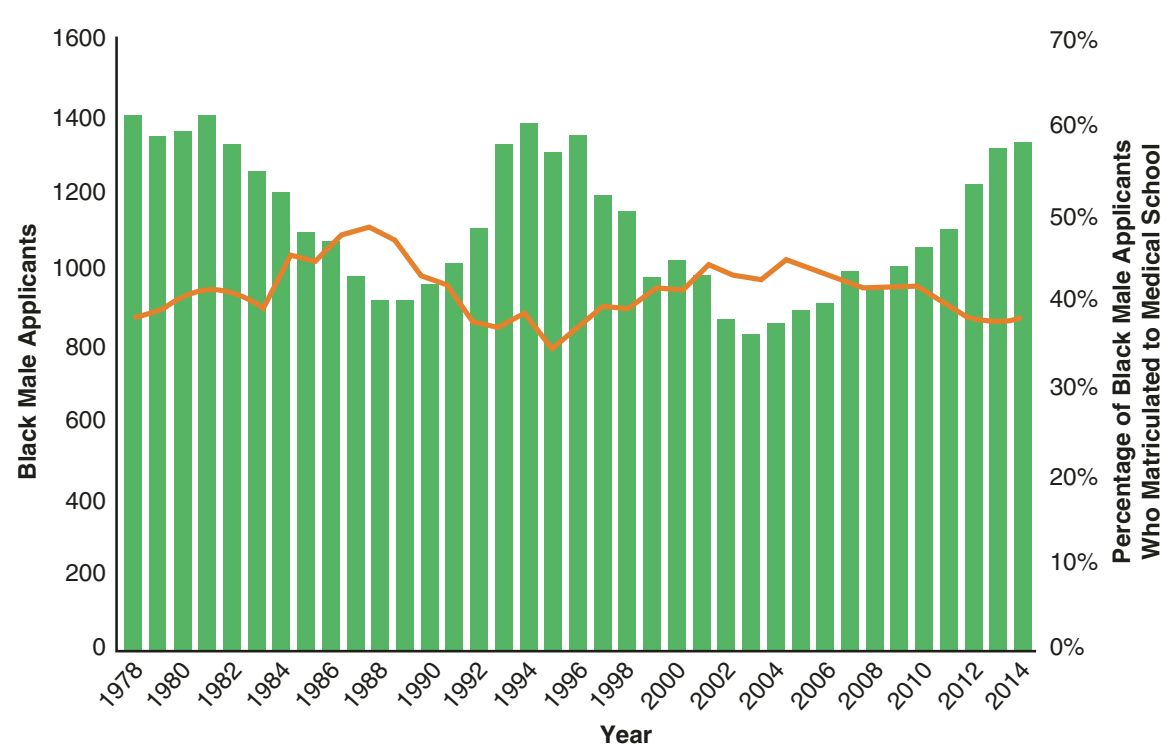

Fig. 10.2 Number of black or African American male medical school applicants (bars) versus percentage of black or African American applicants who matriculated (line), 1978-2014. Source: AAMC Data Warehouse: Applicant and Matriculant File, as of 5/11/2015. (From Laurencin and Murray [2] with permission Springer)

Eva Louise Frazer, MD, an internist and prominent community activist from St. Louis, Missouri [6]. Following an initial White Paper on the subject, a fullscale article was published and disseminated in 2018 [7]. The report detailed the police use of excessive force, and many approaches to reducing the level of violence were suggested, including greater involvement by the community of black physicians who must play a vital role in eradicating this epidemic. More interaction between the police, physicians, and the public was recommended.

The NMA has begun discussions with the National Organization of Black Law Enforcement Executives (NOBLE; https://noblenational.org/) on the issue of violence and the police use of force in the black community. This dialogue has been facilitated by former Norfolk, Virginia, Chief of Police and former NOBLE President John I. Dixon III and Sheila L. Thorne, President and CEO of the Multicultural Healthcare Marketing Group, who have collaborated with the NMA and other medical groups in communities of color to develop strategies to combat this problem, which is spreading explosively throughout the country.

Recently, there has been speculation that exposure to violence has had psychopathological fallout in the black community with the development of post-traumatic stress disorder (PTSD), which is defined as a trauma- or stress-related reaction that may develop in individuals following exposure to an ordeal or an event in which death or physical harm has occurred, is witnessed, or is threatened. This is another example of the public health consequences of violence and police brutality in the black community, leading to a population that may be in need of psychotherapy. 


\section{Mental Illness}

It is often said that being black in America exposes one of necessity to mental illness on a personal, familial, or community level. Mental health issues in the black community have been largely ignored or swept under the carpet. We must bring greater recognition to this problem in order to treat it. According to the US Department of Health and Human Services, African Americans are 20\% more likely than whites to report that they have severe psychological stress [8]. However, many blacks do not present themselves for psychiatric attention because they have a fear of being stigmatized; studies have shown that African Americans view mental illness as highly stigmatizing, resulting in low treatment-seeking [9]. In addition, they fear the criminalization of mental illness, according to Patrisse Cullors of Black Lives Matter [10]. Tied to this is the sudden increase in suicide attempts by young black males, which has been chronicled in a special story by CNN [11], based on a CDC study that was recently released, containing data from 1991 to 2017. This is a prime area for more research and prevention of a serious health problem in the black community. Hopefully, organizations like the Trevor Project, which provides crisis intervention and suicide prevention services primarily to LGBTQ/Q young people, will become more involved in the special situation facing black youth, who are more impacted by poverty, low income, joblessness, racism, and homelessness.

\section{High Maternal Mortality}

High maternal mortality is a problem that the black community has silently dealt with for decades. It has several definitions. One definition is death of a woman while pregnant or within 42 days of end of pregnancy, irrespective of the cause of death. Defined as the number of maternal or pregnancy-related deaths in a given time period per 100,000 live births during the same period, the maternal mortality rate has been rising for American women in general but much more so for black women, who experience more than three times the rate that white women do. In fact, as Fig. 10.3 shows, the statistics for black women in the United States are closer to women from Brazil, Uzbekistan, Malaysia, and Mexico compared to non-Hispanic American white women whose statistical profile resembles that of women in more affluent countries such as Japan, New Zealand, the United Kingdom, and France [12]. There is also a difference in causation of pregnancy-related deaths between blacks and whites, as reported by a study of Maternal Mortality Review Committee data by the Building US Capacity to Review and Prevent Maternal Deaths initiative, a partnership of the Association of Maternal and Child Health Programs (AMCHP), the Centers for Disease Control and Prevention (CDC) Division of Reproductive Health, and CDC Foundation (Fig. 10.4) [13]. The main causes in blacks are cardiomyopathy, preeclampsia, and eclampsia, whereas the principal causes in whites are cardiovascular and coronary conditions, hemorrhage, mental health conditions, and infections. 


\section{MORTALITY GAP FOR U.S. MOMS}

In the U.S., black women who are expecting or who are new mothers died at rates similar to those of the same women in lower-income countries, while the maternal mortality rate for white U.S. mothers more closely resembles rates in more affluent nations.
Source: U.S. ratios (2011-2014) CDC Pregnancy Mortality Surveillance System; Global ratios (2015): UNICEF

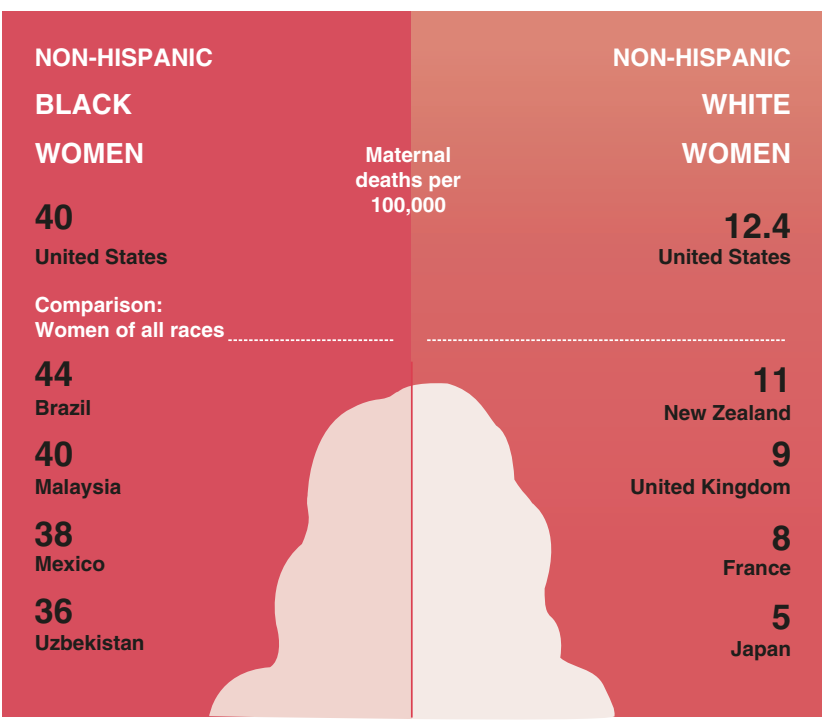

Fig. 10.3 The mortality gap between non-Hispanic black and white women in the United States and comparison with selected countries of the world. (From Roeder [12], with permission. Illustration courtesy of Ben S. Wallace, Harvard T.H. Chan School of Public Health)

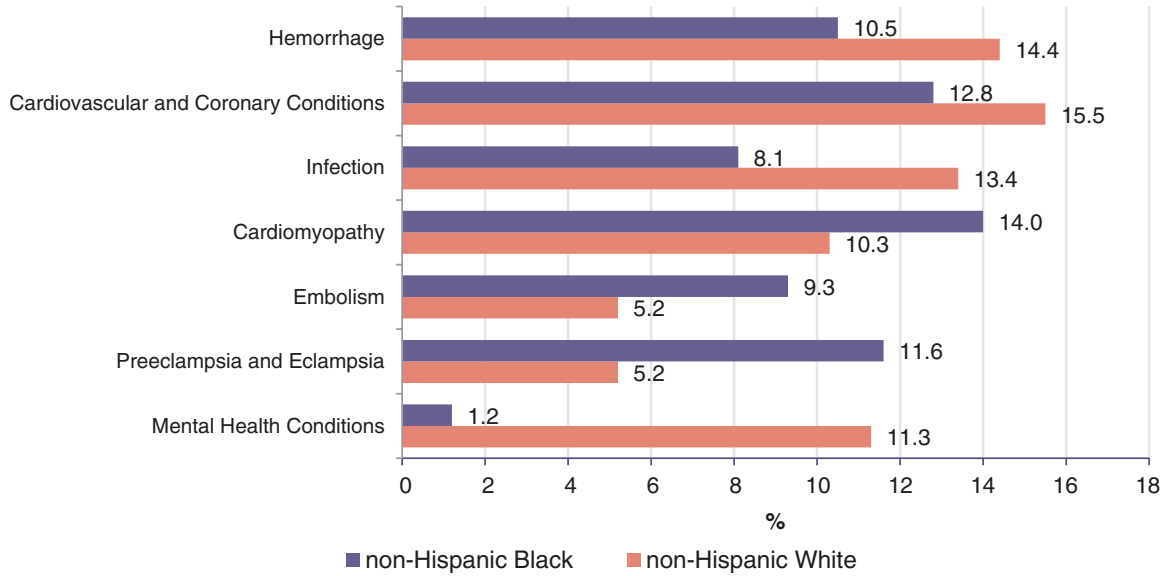

Fig. 10.4 Building US Capacity to Review and Prevent Maternal Deaths. (2018). Report from nine maternal mortality review committees. (Retrieved from http://reviewtoaction.org/Report from_Nine_MMRCs. Accessed 6 Nov 2019)

Members of the Congressional Black Caucus, and Senator Kamala Harris in particular, have expressed grave concern about these disparities in maternal mortality. Senator Harris says that racial bias is part of the cause. Senator Elizabeth Warren agrees. One area of focus is on prevention; it is estimated that about twothirds of black maternal deaths are entirely preventable if more attention is paid 
to socioeconomic determinants of health by eliminating social inequities through the provision of clean drinking water, better housing, improved transportation, and greater access to high-standard healthcare facilities for pre- and postnatal care. However, it should also be recognized that higher mortality in black women transcends social class to some extent in that those who are more affluent and better educated are also exposed to the risk, such as in the case of black tennis star Serena Williams, who almost died from a complication of pregnancy. Obviously, more research is needed in this area. The March of Dimes is one agency that is focusing on this problem, and Congresswomen Alma Adams (D-NC) and Lauren Underwood (D-IL) have launched the Black Maternal Health Caucus to improve outcomes in this problem area. It seeks to raise awareness of the condition in the US Congress so that black maternal health becomes established as a national priority. They are interested in hearing from constituents from throughout the country. They may be reached at their office at 2436 Rayburn House Office Building, Washington, DC, 20515-3312 or by calling their office at 202-225-1510.

We have much work to do to make an impact on the factors causing disparities in healthcare delivery and to protect the lives of all citizens of the United States, and especially of those who are the most vulnerable, such as the black population and other people of color. It is my hope that one day it will be unnecessary to make efforts like this on behalf of discrete segments of our society, because we will all truly be equal. The poem Common Dust by black poet Georgia Douglas Johnson expresses that hope:

And who shall separate the dust.

What later we shall be:

Whose keen discerning eye will scan.

And solve the mystery?

The high, the low, the rich, the poor,

The black, the white, the red,

And all the chromatique between,

Of whom shall it be said:

Here lies the dust of Africa;

Here are the sons of Rome;

Here lies the one unlabeled,

The world at large his home!

Can one then separate the dust?

Will mankind lie apart,

When life has settled back again.

The same as from the start?

As this book was going into production, evidence of a growing awareness of the racial, ethnic, and cultural divide and the importance of recognizing our historical legacy emerged in a photograph that circulated virally on social media and news organizations, showing 15 African American medical students from Tulane University in New Orleans standing in front of the former slave quarters of the Whitney Plantation in Wallace, Louisiana, about 46 miles northwest of New Orleans, on December 14, 2019 (students listed alphabetically: Tivona Batieste, Christen Brown, Carrie Crook, Mashli Fleurestil, Adedoyin Johnson, Alexandria Jones, Sydney Labat, Jean Lafontant, Russell J. Ledet, Jessica Mecklosky, Tiana Roddy, Jasmine Taylor, Rachel 


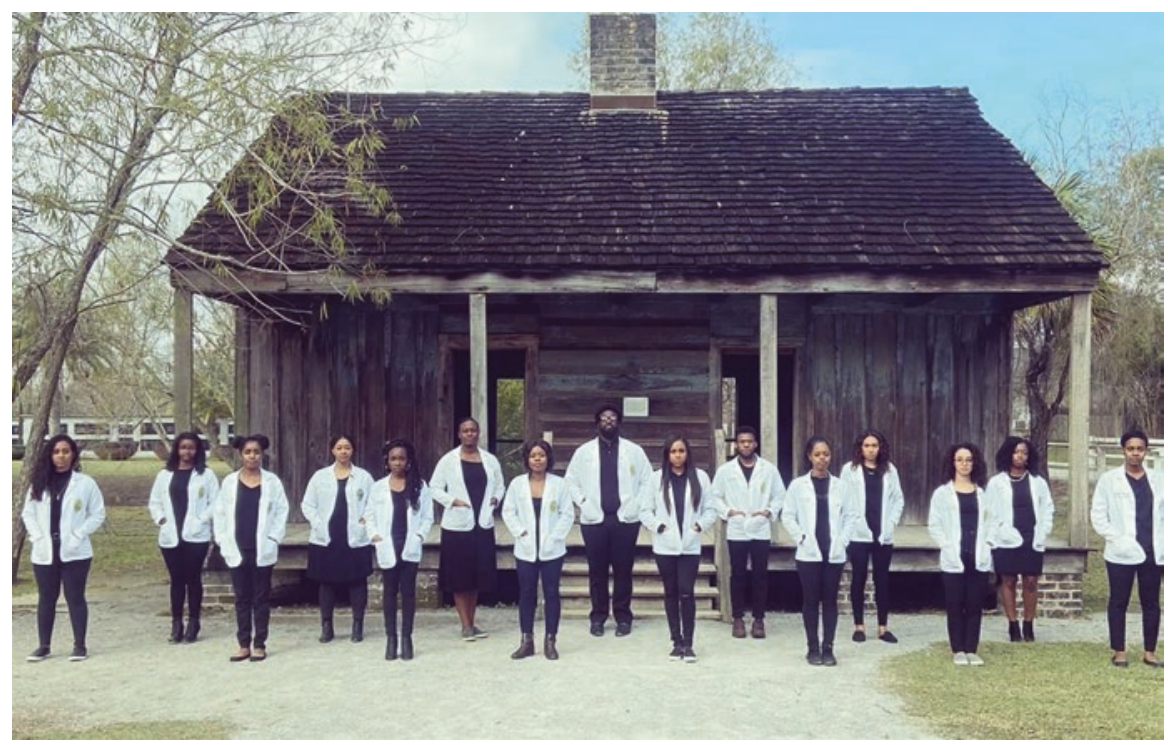

Fig. 10.5 African American medical students from Tulane University in New Orleans standing in front of a former slave quarters of the Whitney Plantation in Wallace, Louisiana, about 46 miles northwest of New Orleans, on December 14, 2019. "We are our ancestors' wildest dreams," student Russell J. Ledet wrote in a tweet sharing a photograph of the moment. (Photograph courtesy of Brian Washington Jr., with permission)

Trusty, Rachel Turner, Jasira Ziglar). "We are our ancestors' wildest dreams," student Russell J. Ledet wrote in a tweet sharing a photograph of the moment (Fig. 10.5). Thus, our saga of Blacks in Medicine has come full circle, from the shackles of slavery to the halls of sophisticated medical schools, and back, to revisit the place where so much suffering occurred. We can thank those students for providing the connection between the brutal past and the bright future that awaits them.

Also, as this book was about to go to press, the coronavirus (COVID-19) pandemic erupted and is still largely uncontrolled at the time of this writing. Although it is not possible to review all aspects of this crisis in this small space, it is important to mention some relevant issues regarding the disproportionate impact that this disease is having on communities of color in the United States. Early data indicates that the occurrence rate and the death rate are disproportionately high in large cities even where African Americans are not the majority of the population. For instance, according to CNN host and journalist Van Jones, who spoke on CNN on April 6, 2020 in an opinion piece titled "Black America Must Wake Up to this Viral Threat", in Milwaukee County, Wisconsin, where 27 percent of the residents are black, almost half of those infected with the virus are black, and 81 percent of those who died of COVID-19 are African American. In Illinois, where blacks make up only 14.6 percent of the population, 28 percent of those affected are black. In Michigan, including Detroit, blacks account for 33 percent of the cases and 40 percent of the deaths. And in Louisiana, where blacks are not in the majority, Governor John Bel Edwards has indicated that almost 70 percent of the deaths are in black people. Why is this happening? One might speculate that the co-morbidities that predominate in black communities such as high rates of heart disease, hypertension, diabetes, asthma, cancer, and other disorders, combined with a high incidence of the 
socioeconomic determinants of health make the black population particularly vulnerable to COVID-19 infection. All of the data have not been gathered because very few cities and states are tracking the incidence and deaths by race and ethnicity, which is necessary to draw a clear picture of what is going on. Without that data, resources and funding such as money from the recently passed $\$ 2$ trillion dollar Stimulus bill may not be appropriately distributed to those in poor communities of color where the need for relief seems to be the greatest. And more information and data should be demanded from the Centers for Disease Control and Prevention (CDC) which so far has been reluctant to release anything to the public, despite requests made by some congressmen including Senator Wyden of Oregon. We can and must do more to avert unnecessary deaths and suffering from this deadly scourge. Blacks, including African American organizations, must come to the rescue of themselves before it is too late.

\section{References}

1. National Academies of Sciences, Engineering, and Medicine. An American Crisis: The Growing Absence of Black Men in Medicine and Science: Proceedings of a Joint Workshop. Washington DC: National Academies Press. 2018. https://www.nap.edu/catalog/25130/anamerican-crisis-the-growing-absence-of-black-men-in. Accessed 30 Oct 2019.

2. Laurencin CT, Murray M. An American crisis: the lack of black men in medicine. J Racial Ethnic Health Disparities. 2017;4:317-21.

3. Alsan M, Garrick O, Graziani GC. Does diversity matter for health? Experimental evidence from Oakland. NBER Working Paper No. 24787. Issued Jun 2018, Revised Aug 2019. Cambridge, MA: National Bureau of Economic Research, 2018. https://www.nber.org/papers/ w24787. Accessed 30 Oct 2019.

4. Cantor JC, Miles EL, Baker LC, Barker DC. Physician service to the underserved: implications for affirmative action in medical education. Inquiry. 1996;33(2):167-80.

5. Beeler WH, Mangurian C, Jagsi R. Unplugging the pipeline - a call for term limits in academic medicine. N Engl J Med. 2019;381(16):1508-11.

6. Jones A. National Medical Association seeks to address violence in the African American community. Philadelphia Tribune. 2 Aug 2017. https://www.nmanet.org/news/359921/NMAseeks-to-address-violence-in-the-African-American-community.htm. Accessed 30 Dec 2019.

7. Frazer E, Mitchell RA, Nesbitt LS, Williams M, Mitchell EP, Williams RA, Browne D. The violence epidemic in the African American community: a call by the National Medical Association for comprehensive reform. J Nat Med Assoc. 2018;110(1):4-15.

8. Mental Health America. Black \& African American communities and mental health. https:// www.mhanational.org/issues/black-african-american-communities-and-mental-health. Accessed 30 Oct 2019.

9. Ward EC, Wiltshire JC, Detry MA, Brown RL. African American men and women's attitude toward mental illness, perceptions of stigma, and preferred coping behaviors. Nurs Res. 2013;62(3):185-94.

10. Black Lives Matter's Patrice Cullors on the criminalization of mental illness. https://www. mic.com/. 11 Oct 2019. https://www.mic.com/p/black-lives-matters-patrisse-cullors-on-thecriminalization-of-mental-illness-19209822. Accessed 30 Oct 2019.

11. Christensen J. Suicide attempts by black teens are increasing, study says. https://www.cnn. com/2019/10/14/health/black-teen-suicide-attempts-study/index.html. Accessed 30 Oct 2019.

12. Roeder A. America is failing its black mothers. Harvard Public Health. Winter 2019. https:// www.hsph.harvard.edu/magazine/magazine_article/america-is-failing-its-black-mothers/. Accessed 30 Oct 2019.

13. Review to Action. Building U.S. capacity to review and prevent maternal deaths. Report from nine maternal mortality review committees. https://reviewtoaction.org/Report_from_Nine_ MMRCs. Accessed 21 Oct 2019. 